\title{
PREYING FREQUENCY OF WHITE-THROATED KINGFISHER, Halcyon smyrnensis (LINNAEUS 1758)
}

\author{
Habibon Naher ${ }^{1}$ and Noor Jahan Sarker ${ }^{2}$ \\ ${ }^{1}$ Department of Zoology, Jagannath University, Dhaka-1100 \\ ${ }^{2}$ Department of Zoology, University of Dhaka, Dhaka-1000
}

\begin{abstract}
A study was conducted on 'Preying frequency of White-throated Kingfisher, Halcyon smyrnensis (Linnaeus 1758) in Bangladesh' from September 2008 to September 2011 at Nikunja-1 in Dhaka City Corporation area. The objectives of the study were to know the average preying frequency per day in different months and seasons. Scan sampling method was followed to study the kingfishers' behaviour. At regular interval (5 minutes), day long observation was made with some observatory equipments. It preyed $4.1 \pm 2.3$ times per day on an average. They had bimodal feeding patterns, at morning (0701-1200 h) and afternoon (1401-1800 h). At noon they avoided preying. December was the highest preying month and summer was the highest unsuccessful preying season in the year. The food items composed of $36.6 \%$ arthropods and $61.1 \%$ fishes. Arthropods were preyed for 1.5 times and fishes for 2.5 times on an average per day. In association with arthropods and fishes they also preyed on amphibians and reptiles occasionally. Arthropods were preferred highly during non breeding season but fishes were preferred in breeding season for saving time and energy.
\end{abstract}

Key words: Preying frequency, White-throated Kingfisher, Halcyon smyrnensis, Bangladesh.

\section{INTRODUCTION}

White-throated Kingfisher (H. smyrnensis) is a common species of a variety of habitats, mostly open country in plains with trees, electric wires and other perches (Ali et al. 2010a). It is found in Turkey, northern and central Israel, and Egypt through to Iraq, Iran, Afghanistan, northwestern India (Ali and Ripley 1983) and parts of Southeast Asia (del Hoyo et al. 2001, Fry et al. 1992).

In India, studies are limited to casual observations and feeding behaviours and breeding of White-throated Kingfisher (H. smyrnensis) (Ali et al. 2010b, Asokan et al. 2009, Balasubramanian 1992, Hore et al. 1991, Mukherjee 1975, Oommen and Andrews 1996 1998, Palkar et al. 2009, Sen 1944, Sirinvasulu 2004, Yahya and Yasmin 1991). White-throated Kingfisher is well known for its versatile food and feeding habits (Ali and Ripley 1983, Mukherjee 1975). Many researchers studied about the diets of the White-throated Kingfisher (Ali 1996, Ali et al. 2010a, Asokan et al. 2009, Burton 1998, Roberts and Priddy 1965, Roza et al. 1995, Soud et al. 2010, Yahya and Yasmin 1991) in India and Srilanka. In Bangladesh, studies on the Kingfishers are scanty. Some causal information is found in Bangladesh about the kingfishers (Ahsan and Saeed 1990, Husain 1979, Husain et al. 1983, Islam et al. 1999, Khan 1982, 1986, Reza et al. 
2003, Sarker 1985, 1986, 1989). Except these observations nothing is known about the Kingfishers in Bangladesh.

Like any other creatures, number of birds including kingfishers is declining, causing imbalance in nature. Although kingfishers are still seen in our wetland, its poulation are declining due to different factors, as seen in the past to the present days. Their uses are seen diversified (Animal Diversity 2007, Fry et al. 1992, Wikipedia 2010). Although they may get benefit from human dams and fish farming, they are at risk of poisoning through bioaccumulation of pollution and toxins in their fish prey (Rayner et al.1991). Thus, necessary measures should be taken immediately to conserve their population in nature. Therefore, one should know the monthly and seasonal variation of preying and preying frequency during breeding and non breeding season. On the basis of this study one can take necessary measures for their conservation and management. Hence, the present study investigates 'the preying frequency of White-throated Kingfisher (H. smyrnensis) in Bangladesh'.

\section{MATERIALS AND METHODS}

The study on 'Preying frequency of Whitethroated Kingfisher (H. smyrnensis) in Bangladesh' was done from September 2008 to September 2011. The study was carried out in Nikunja-1, Uttara, Dhaka, Bangladesh. This area is under the Dhaka City Coporation and on the west side of Dhaka Airport highway. There are two Lakes, one on the east $\left(23^{\circ} 49^{\prime} 14.81^{\prime \prime}\right.$ to $23^{\circ} 49^{\prime} 36.04^{\prime \prime} \mathrm{N}$ latitudes and $90^{\circ} 25^{\prime} 02.38^{\prime \prime}$ to $90^{\circ} 25^{\prime} 12.30^{\prime \prime} \mathrm{E}$ longitudes) and the other on the west side $\left(23^{\circ} 49^{\prime} 26.33^{\prime \prime}\right.$ to $23^{\circ} 49^{\prime} 30.77^{\prime \prime} \mathrm{N}$ latitudes and $90^{\circ} 24^{\prime} 55.60^{\prime \prime}$ to $90^{\circ} 24^{\prime} 59.82^{\prime \prime} \mathrm{E}$ longitudes) of the Nikunja-1 residential area. The size of the eastern lake is $668.5 \times 17.07 \mathrm{~m}$ and western lake is $218.13 \times 75.05 \mathrm{~m}$. The northern and southern side of Nikunja-1 is surrounded by Nikunja 2 residential area and Dhaka Cantonment Golf field respectively.
Preying frequency was observed at least once a week in non-breeding season and thrice in a week in breeding season. The birds were watched from dawn to dusk as the species are diurnal. Behavioural data were collected using the focal animal sampling technique of Altmann (1974). In each one hour, there were three 15-minute continuous monitoring periods followed by a 5minute break. During each 15-minute period, only one bird was monitored. If any important activities were found on another bird those were also noted. A total of 1672 hours in 144 days were spent in the field and 5016 scans were made during the study period.

During preying, the frequency of preying (no. of dive into water or no. of plunge in the air for successful or unsuccessful preying) of different food items by each individual was noted per scan. The average preying frequency per day, per hour and per month in a year and even during breeding and non-breeding season was noted. Daily, monthly and seasonal variation of preying frequency of arthropods and fishes in a year and even during breeding and non breeding season was also noted. To find out the seasonal variation, the year is divided into three seasons, November to February as winter, March to June as summer and July to October as monsoon.

\section{RESULTS AND DISCUSSION}

\section{Preying frequency}

H. smyrnensis preyed on a number of different species and more than $70 \%$ attempt was successful $(n=267)$. They preyed on different species of food of which fishes $(61.1 \%)$ were highly preferred. On an average, they preyed $4.1 \pm 2.3$ times per day.

\section{Preying at different day periods}

The preying frequency insignificantly varied at different day periods $\left(\chi^{2}=2, \mathrm{df}=9, \mathrm{p}>0.05\right)$. The increasing rate was found from 0701-1000 h. After a long overnight starvation the bird started to prey from early morning but the frequency was related with the sunlight when the highest frequency was at 0901-1000 h. But after $1001 \mathrm{~h}$ the frequency 
was decreasing and at mid-day (1201-1400 h) (n = 193) they avoided preying. From $1401-1700 \mathrm{~h}$ the preying frequency again increasing while the highest was 1501-1700 $\mathrm{h}$ which need for their overnight energy requirements (Fig. 1). It was also related with their sunlight. The preying frequency was decreasing as the sunlight decreasing.

Several studies in Corbett National Park, Bandhargarh National Park, and Sundarban National Park also found most hunting by $H$. smyrnensis during the morning or comparatively less in the evening hours (EcoIndia 2008). The White-throated Kingfisher had a typically bimodal feeding pattern, one during the morning (06:0009:00 hrs) and another during the evening (15:0018:00 hrs) as shown for other species (Ali et al. 2010a, Asokan 1995, Evers 1994, Natarajan 1991, Ramachandran 1998, Rodway 1998, Sivakumaran and Thiyagesan 2003). Feeding activity in the late evening may reflect their need for their overnight energy requirements (Kelly 1998). The amounts of time spent on scanning activity within time blocks and habitats by the White-throated Kingfisher were inversely correlated to the availability of prey (Ali et al. 2010a).

\section{Monthly preying frequency}

The average preying frequency per day was insignificantly varied in different months $\left(\chi^{2}=\right.$ $15.6, \mathrm{df}=11, \mathrm{p}>0.05)$. There were two peaks in a year. First, in the month of November and December (Fig. 2) when they preyed on arthropods, it was their non breeding season when resting was occurred mainly and arthropods were available then. The other peak was in the month of April and May when they preyed mainly on fishes which was their peak breeding months $(n=193)$ and they need a large amount of food for their extra energy.

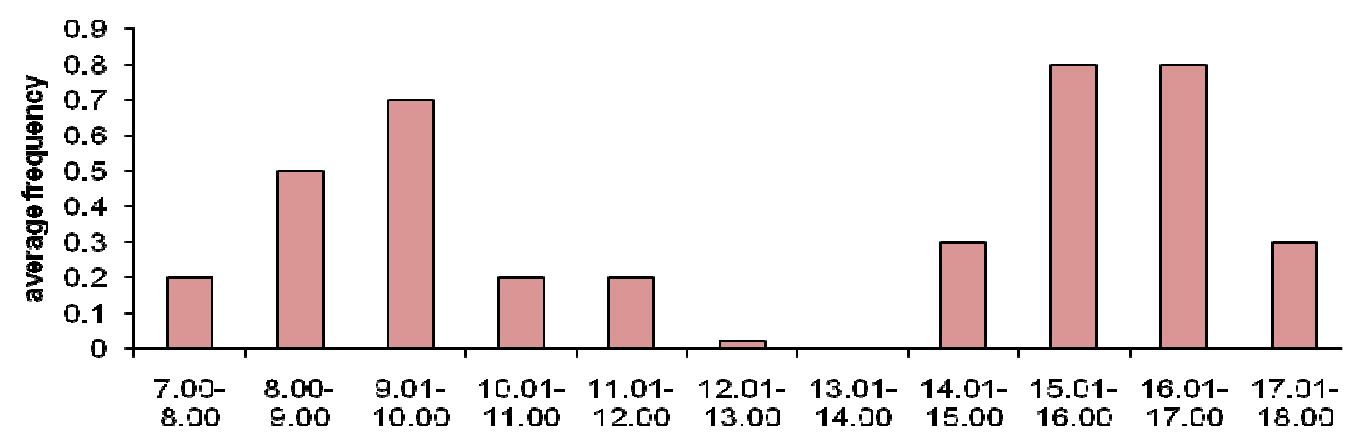

Fig. 1. Preying frequency of total food items at different day periods.

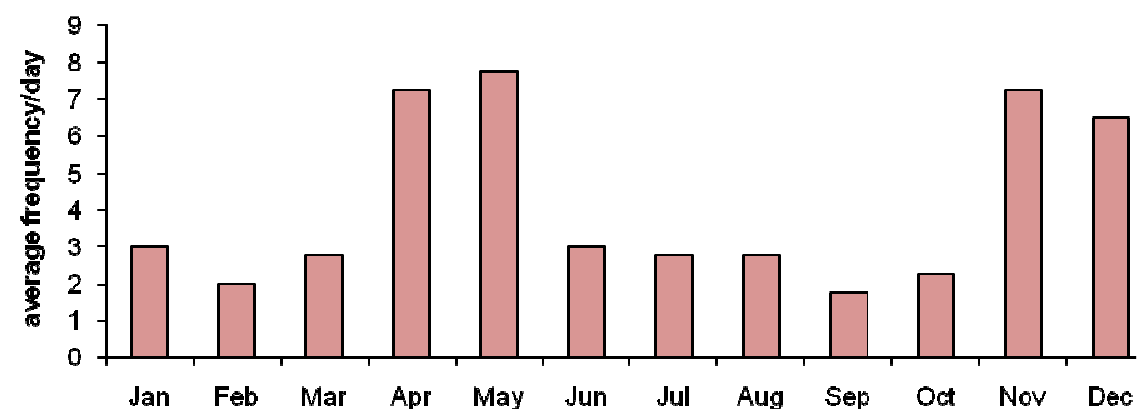

Fig. 2. Monthly preying frequency. 


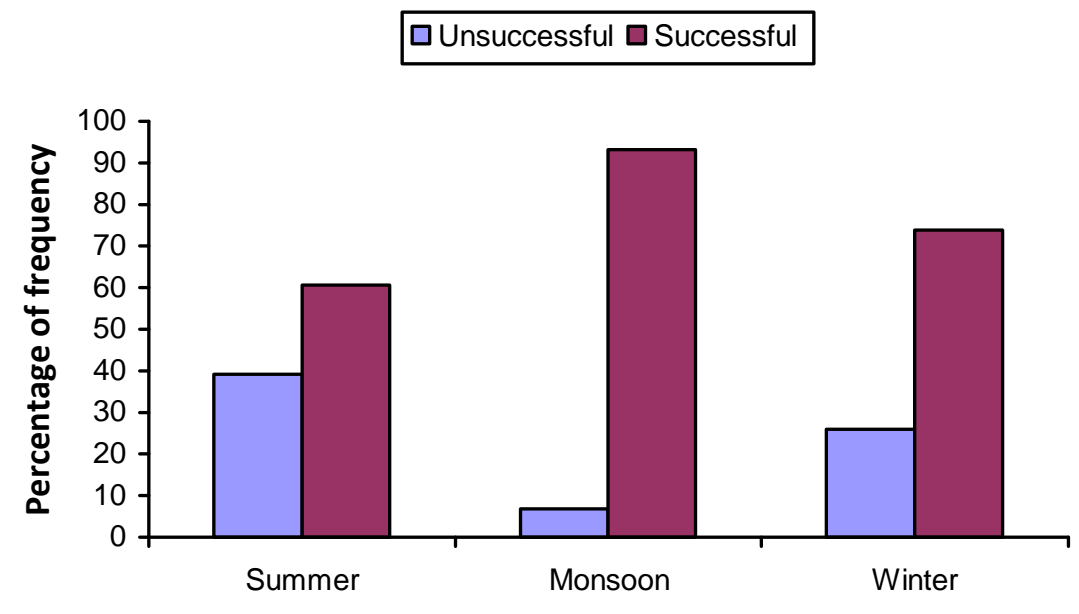

Fig. 3. Unsuccessful and successful preying frequency in different seasons.

\section{Seasonal preying $(\mathbf{n}=\mathbf{1 9 3})$}

The average preying frequency per day was insignificantly varied in different seasons $\left(\chi^{2}=1.1\right.$, $\mathrm{df}=2, \mathrm{p}>0.05)$. It was the highest in summer (5.02 times/day) when the breeding was occurred ad they had a great demand for food and lowest in monsoon (2.3 times/day) when the aquatic bodies were inundated and breeding season was finished. Ali et al. (2010a) reported that the scanning activity of $H$. smyrnensis was greater in monsoon and post-monsoon periods when insect or other prey was abundant and lower in the summer when prey was in short supply at Cauvery Delta in Southern India. Differences in recorded seasonal feeding activity inferred that $H$. smyrnensis fed more often during the summer and less during the monsoon (Asokan et al. 2009) at Tamil Nadu in India, where the food resources were generally abundant during the summer, and so the study species took a variety of prey, from insects to large crabs, but in these habitats, insects predominated. They further mentioned that during rainy season (September to January) when the weather was much warmer and rivers and ponds are mostly inundated, $H$. smyrnensis fed aquatic animals like fish and frogs, while during the drier months (February to August) they fed mainly terrestrial 42 animals at Tamil Nadu in India. It shows that taking of particular food items in particular season is rather similar to Tamil Nadu with that of Bangladesh. Ali et al. (2010a) reported that during the monsoon, the study area (Cauvery Delta in Southern India) is generally in wet condition due to the northeast monsoon rainfall that greatly affected prey species (mainly insects) distributions. In the post-monsoon period, cold temperatures might be expected to force kingfishers to devote more time to scanning, while the reverse might be true during the summer. Asokan et al. (2009) mentioned that during the drier months (February to August), the H. smyrnensis fed mainly terrestrial animals found at Tamil Nadu in southern India.

The preying attempt was not successful in all the cases. Some preying attempt was unsuccessful (27.7\%) which was recorded as the highest in summer and lowest in monsoon (Fig. 3). It may be related with the availability of prey species.

\section{Preying on different food items in a year}

As preying frequency on different food items varied at different day periods, months and seasons, which were more or less dependent on the availability of the food items in the environments, so hourly, monthly and seasonal preying frequency

ECOPRINT VOL 22, 2015 
of different food items are described below separately.

\section{Preying on arthropods $(\mathbf{n}=70)$}

Out of total preying food items, the arthropods comprised of $36.6 \%$ in present study whereas Asokan et al. (2009) reported it $83 \%$ in southern India. It preyed 1.5 times/day arthropods on an average in the study period. Preying frequency of arthropods was not significantly varied at different day periods in a day $\left(\chi^{2}=6.1, \mathrm{df}=10, \mathrm{p}>0.05\right)$. It was the highest at 1601-1700 h (Fig. 4) for being a long overnight starvation period.

Preying frequency of arthropods varied monthly but it was statistically significant $\left(\chi^{2}=\right.$ $16.4, \mathrm{df}=11, \mathrm{p}<0.05)$. In the month of June through August (Fig. 5), this kingfisher avoided to prey on the arthropods while it remained busy for the caring of their nestlings. The highest frequency was found in December which was their non breeding month and arthropods were available then.

Preying frequency of arthropods varied to some extent seasonally but it was statistically insignificant $\left(\chi^{2}=2.6, \mathrm{df}=2, \mathrm{p}>0.05\right)$. The highest was in winter (Fig. 6) because the arthropods are more available in winter season than in comparison with other seasons. It was so because in winter season as the water rather remains calm and quite and thus the number of arthropods increases in number without any natural disasters. Dhindsa and Saini (1994) reported that birds stand supreme among vertebrates as enemies of insects because they are highly mobile and are able to congregate quickly in large numbers when sudden outbreaks of insect pests occur. In rainy months, most of the larvae, pupae or nymphs of arthropods are rather washed away due to heavy rain or flood water or adults are destroyed due to storm and high wind.

\section{Preying on fishes $(n=118)$}

Out of preying food items, fishes comprised of $61.1 \%$. It preyed 2.5 times per day on an average. Preying frequency of fishes varied at different day periods but it was not statistically significant $\left(\chi^{2}=\right.$ $3.1, \mathrm{df}=10, \mathrm{p}>0.05)$. Fishes were preyed on all through the day. There were two peaks (0801-1000 $\mathrm{h}$ and1501-1600 h) for H. smyrnensis (Fig. 4). Highest frequency was during 0801-1000 h when they were very much hungry after long overnight starvation period and 1501-1600 h for overnight energy requirements. No or little fish was preyed on at $1300-1400 \mathrm{~h}$ when they preferred to take rest.

\section{$\square$ arthropods $\square$ fishes $\square$ amphibians $\square$ reptilles}

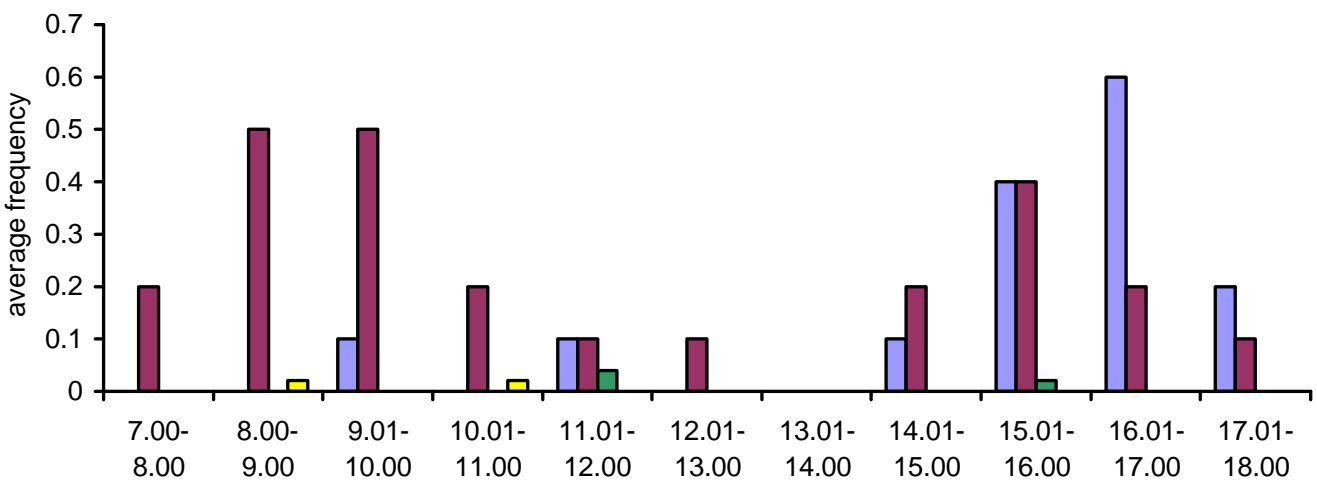

Fig. 4. Preying frequency of different food items at different day periods. 


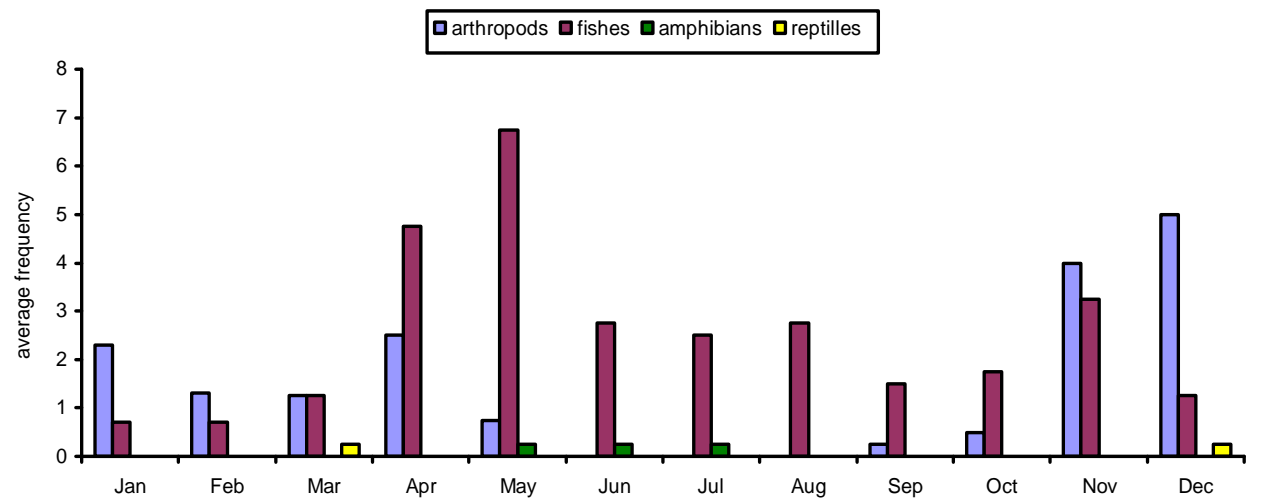

Fig. 5. Monthly preying frequency of different food items.

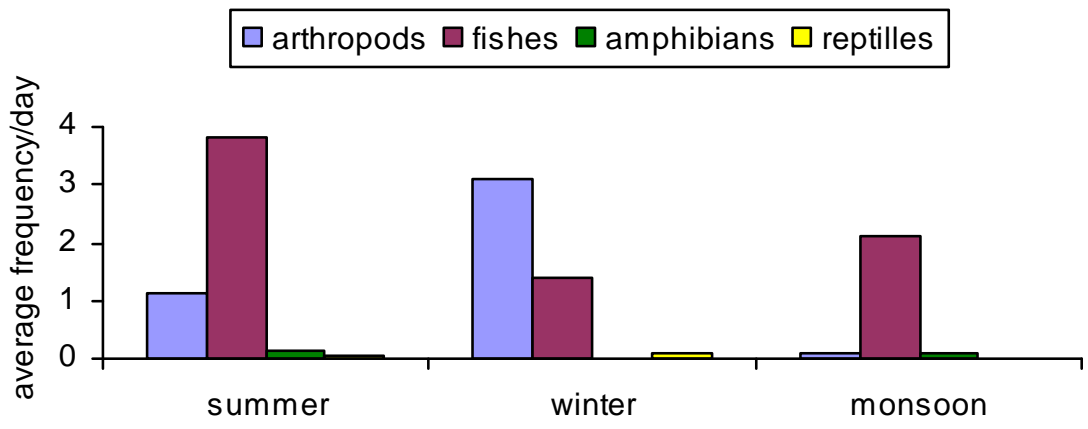

Fig. 6. Seasonal preying frequency of different food items.

Preying frequency of fishes varied monthly but it was not statistically significant $\left(\chi^{2}=1.5, \mathrm{df}=11\right.$, $\mathrm{p}>0.05)$. In the month of April and May, $H$. smyrnensis preyed on at the highest rate because it was their peak breeding months (Fig. 5).

The average preying frequency per day varied in different seasons but it was not statistically significant $\left(\chi^{2}=0.82, \mathrm{df}=2, \mathrm{p}>0.05\right)$. The highest frequency was in summer in all the cases except reptiles (Fig. 6). It was related with their breeding season when they need more food.

H. smyrnensis also preyed on amphibians and reptiles occasionally. Amphibian was recorded only in May to July (Fig. 5) when it reared their nestlings and supplied amphibians to the nestlings mainly because the nestlings need different types of food for their growth and developments. This was also related with the availability of food items in nature. Reptile was preyed in the homestead area when the bird had got chance. According to Asokan et al. (2009), it preyed crabs, fishes, amphibians and reptiles which comprised of about $16 \%$ of its diet in Tamil Nadu of southern India.

Statistical interference of different food items with total preying frequency in different months and seasons (Table 1) is also analyzed in case of both species.

\section{Preying during breeding and non breeding seasons}

The average preying frequency per day during breeding and non breeding seasons was more or less same. Arthropods were preferred highly during non breeding season but fishes were preferred in breeding season for saving time and energy. 
Amphibians and reptiles were recorded occasionally of which amphibians were recorded only in breeding season but reptiles were recorded both in breeding and non breeding season (Fig. 7). It was mainly depend on getting chance.

Preying of different food items varied at different day periods during breeding and non breeding seasons but it was not statistically significant (breeding: $\chi^{2}=1.5, \mathrm{df}=10, \mathrm{p}>0.05$; non breeding, $\chi^{2}=2.3$, df $\left.=5, \mathrm{p}>0.05\right)$. Preying frequency was highly preferred at 0801-0900 $\mathrm{h}$ and 1501-1700 h during breeding $(\mathrm{n}=100)$ but it was at 1501-1700 $\mathrm{h}$ during non breeding season $(\mathrm{n}=$ 93) (Fig. 8). During breeding, they had a pressure for the nestlings in the morning after a long overnight starvation period afternoon for going to overnight starvation. But in non breeding season in the afternoon they mainly preyed on arthropods which were available then.

Table 1. Statistical interference of different food items with total preying frequency in different months and seasons.

\begin{tabular}{|c|c|c|c|c|}
\hline \multirow[t]{2}{*}{ Variables } & \multicolumn{2}{|c|}{ Month } & \multicolumn{2}{|c|}{$\begin{array}{l}\text { Season } \\
\end{array}$} \\
\hline & $r(d f=1, p=0.05)$ & $\begin{array}{c}\text { Statistical } \\
\text { interference }\end{array}$ & $r(d f=2, p=0.05)$ & $\begin{array}{c}\text { Statistical } \\
\text { interference }\end{array}$ \\
\hline Fishes : total food items & 0.7 & Significant & 0.7 & Insignificant \\
\hline Arthropods : total food items & 0.6 & Significant & 0.4 & Insignificant \\
\hline Amphibians : total food items & 0.107 & Insignificant & 0.15 & Insignificant \\
\hline Reptiles : total food items & 0.108 & Insignificant & 0.1 & Insignificant \\
\hline Fishes : arthropods & -0.09 & Insignificant & -0.44 & Insignificant \\
\hline
\end{tabular}

$\square$ Breeding season $\square$ Non-breeding season

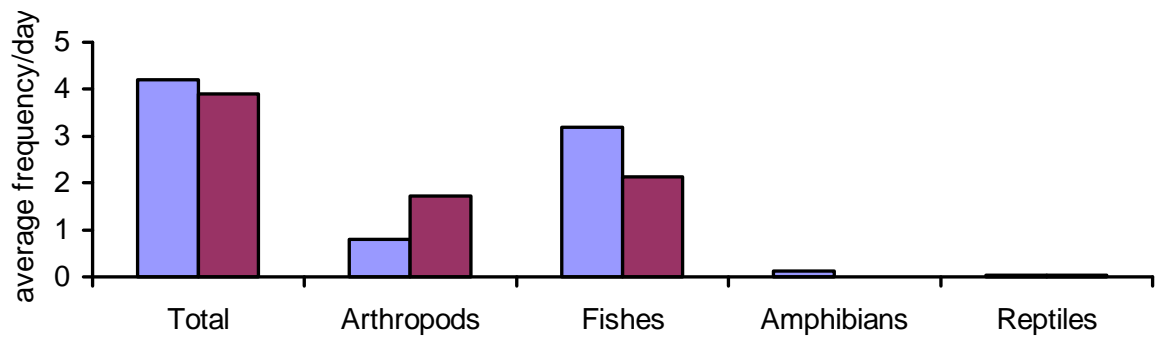

Fig. 7. Preying of different food items in breeding and non breeding seasons.

$\square$ Breeding $\square$ Non breeding

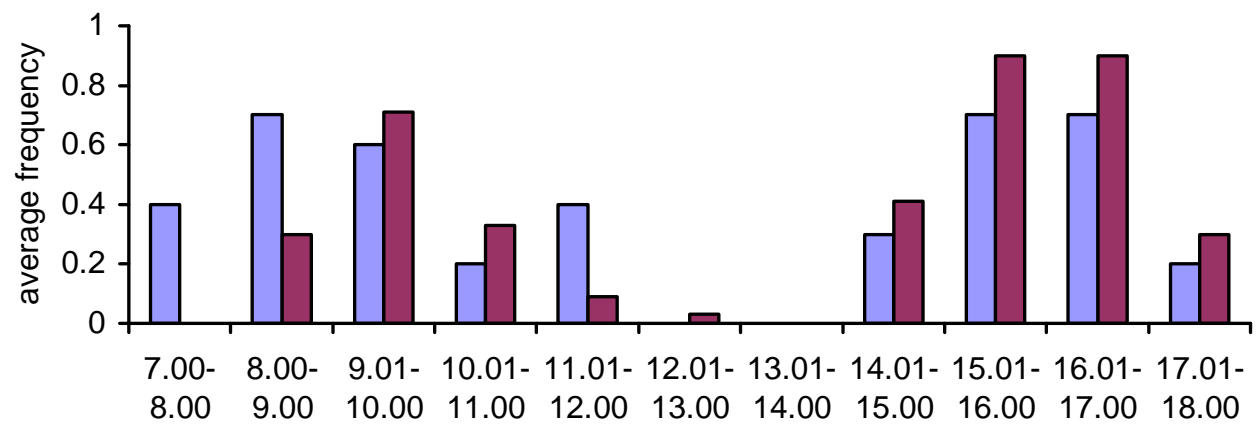

Fig. 8. Preying frequency of different food items at different day periods in breeding and non breeding seasons. 
Table 2. Statistical interference of different food items with total preying frequency during breeding and non breeding season at different day periods.

\begin{tabular}{lcccccc}
\hline Parameters & \multicolumn{2}{c}{ Breeding season } & \multicolumn{3}{c}{ Non breeding season } \\
& $\mathbf{r}(\mathbf{d f = 1 1})$ & $\mathbf{P}$ & $\begin{array}{c}\text { Statistical } \\
\text { interference }\end{array}$ & $\mathbf{r}(\mathbf{d f}=\mathbf{9})$ & $\mathbf{P}$ & Statistical interference \\
\hline Fishes : total food items & 0.89 & 0.01 & Significant & 0.52 & 0.05 & Insignificant \\
& & & Insignificant & 0.73 & 0.01 & Significant
\end{tabular}

Arthropods : total food items $\quad 0.54 \quad 0.05$

Fishes :arthropods

$0.14 \quad 0.05 \quad$ Insignificant

Table 3. Statistical interference of different food items with total preying frequency in different months during breeding and non breeding seasons.

\begin{tabular}{lcccccc}
\hline Parameters & $\mathbf{r}(\mathbf{d f}=\mathbf{4})$ & $\mathbf{p}$ & $\begin{array}{c}\text { Statistical } \\
\text { interference }\end{array}$ & r (df=4) & $\begin{array}{c}\text { P } \\
\begin{array}{c}\text { Statistical } \\
\text { interference }\end{array}\end{array}$ & $\begin{array}{c}\text { Significant } \\
\text { Insignificant }\end{array}$ \\
\hline Fishes : total food items & 0.94 & 0.01 & Significant & 0.91 & 0.05 & - \\
Arthropods : total food items & 0.44 & 0.05 & Insignificant & 0.36 & - & Insignificant \\
Reptiles : total food items & -0.288 & & Insignificant & 0.54 & Insignificant \\
Fishes : arthropods & 0.124 & & Insignificant & -0.03 & \\
\hline
\end{tabular}

\begin{tabular}{|ll}
\hline Fishes breeding & $\square$ Fishes non-breeding \\
$\square$ Arthrpods breeding & $\square$ Arthrpods non-breeding \\
\hline
\end{tabular}

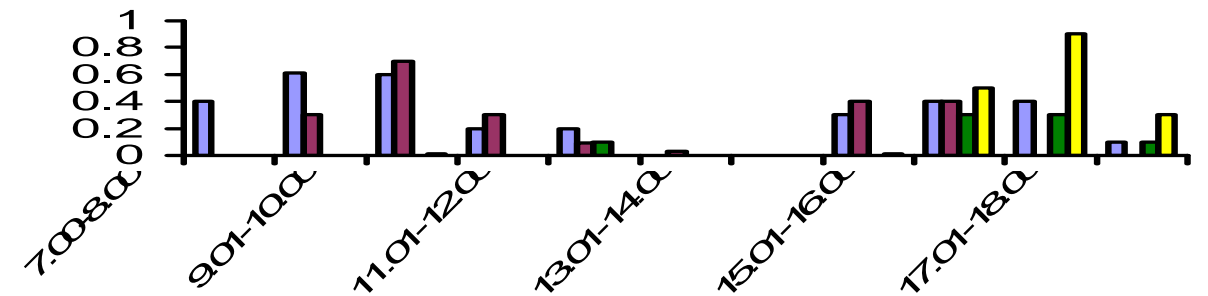

Fig. 9. Preying frequency of arthropods and fishes at different day periods during breeding and non breeding seasons.

The statistical interference of different food items with total preying frequency at different day periods during breeding and non breeding seasons (Table 2) and months (Table 3 ) is also analyzed.

The average preying frequency of the food items at different day periods during breeding season was significantly correlated with the average frequency during non breeding season $(\mathrm{r}=0.73, \mathrm{n}=11, \mathrm{p}<0.01)$. The average preying 46 frequency of arthropods and fishes at different day periods during breeding and non breeding seasons is also mentioned in Table 2.

Preying of arthropods during breeding and non breeding seasons

Average preying frequency of arthropods varied per day during breeding and non breeding seasons but it was not statistically significant

ECOPRINT VOL 22, 2015 
(breeding: $\chi^{2}=2.3, \mathrm{df}=10, \mathrm{p}>0.05$; non breeding: $\chi^{2}=8.5$, df $\left.=10, \mathrm{p}>0.05\right)$. During breeding (1101-1200 $\mathrm{h}$ and 1501-1800 h) and non breeding season (0901-1000 h and 1401-1800 h), it frequently preyed on arthropods while the highest frequency was recorded at 1601-1700 h both in breeding $(\mathrm{n}=22)$ and non breeding seasons $(\mathrm{n}=$ 48) (Fig. 9) because arthropods were available then mainly. They preyed on large arthropods during breeding which were supplied for the growth of nestlings.

\section{Preying on fishes during breeding and non breeding seasons}

Average preying frequency varied at different day periods during breeding and non breeding seasons but it was not statistically significant (breeding: $\chi^{2}=3.7$, df $=10, \mathrm{p}>0.05$; non breeding: $\chi^{2}=4.9$, df $\left.=10, \mathrm{p}>0.05\right)$. During breeding season, $H$. smyrnensis preyed on all day round except noon both in breeding $(\mathrm{n}=71)$ and non breeding seasons $(n=44)$ (Fig. 9). It was highly recorded during 0801 to $1000 \mathrm{~h}$ in breeding season but at 0901-1000 $\mathrm{h}$ in non breeding season.

The relationship of preying frequencies of different food items at different day periods between breeding and non breeding seasons are mentioned in Table 3.

\section{CONCLUSION}

From this study it is known that they preyed a very small amount of fishes and large amount of arthropods as the fish farmer known that they are harmful for fish farming. It occasionally preyed on amphibians and reptiles. Actually it preyed on those animals which are available for them or if the chance arises. The preying frequency was varied hourly, daily, monthly and seasonally. It varied during breeding and non breeding seasons. During breeding season the preying frequency was found more because they had to rear the nestlings. Even during breeding, they preferred to prey on fishes because they had a great demand for themselves and their nestlings and it is easy to catch than other food items. It is not possible to fulfill their great demand by preying of a very small sized animals like arthropods and it had not possible to get a long leisure time for preying a large quantity of arthropods during breeding season. But if they had got chance to catch other animals they got it. They are beneficial to the aquatic environment as they preyed comparatively weaker and diseased fishes and harmful insects. So they are beneficial for preying harmful pests. For reducing aquatic bodies and nesting habitats their population is declining at an alarming rate. Thus necessary measures should be taken immediately for conserve their population in nature as well as the aquatic environment.

\section{ACKNOWLEDGEMENTS}

The author is grateful to the Ministry of Science, Information and Communication Technology for funding the research. She expresses her heartiest gratitude to Mr. Tauhid Uddin Ahmed, Ex-Principal Scientific Officer, IECDR, Mohakhali, Dhaka, Bangladesh for making helpful and constructive comments to enrich this manuscript and for identifying the arthropods. The author is also grateful to Professor Dr. M. Farid Ahsan, Department of Zoology, University of Chittagong, Chittagong to give me continuous support, valuable advice and cordial co-operation during the time of my research work. He made many critical comments which helped to enrich the manuscript.

\section{REFERENCES}

Ahsan, M.F. and M.A. Saeed. 1990. Food and feeding habits of some piscivorous birds of Chittagong. Journal Asiatic Society, Bangladesh, Sci. 16(1):39-45.

Ali, A.M.S., S. Asokan and R. Manikannan. 2010a. Habitat-related density and activity patterns of the White-throated Kingfisher Halcyon smyrnensis in Cauvery Delta, Southern India. Podoces 5(1):54-62. 
Ali, A.M.S., S. Asokan and R. Manikannan. 2010b. Observations on nesting ecology of White-throated Kingfisher Halcyon smyrnensis (Aves: Coraciiformes) in Cauvery Delta, Tamil Nadu, Southern India. Journal of Ecology and The Natural Environment 2(7):134-139.

Ali, S. 1996. The Book of Indian Birds. $12^{\text {th }}$ Revised and enlarged edition. Natural History Society, Mumbai. 345 pp.

Ali, S. and S.D. Ripley. 1983. Handbook of The Birds of India and Pakistan. Vol. 4. Oxford University Press, New York, 265 pp.

Altmann, J. 1974. Observational study of behaviour: Sampling methods. Behav. 49:227267.

Animal Diversity. 2007. Available at http://animal diversity.ummz.umich.edu/site/accounts/infor mation/ Halcyon_smyrnensis.html.

Asokan, S. 1995. Ecology of the Small Green Beeeater, Merops orientalis Latham 1801 with Special Reference to Its Population, Feeding and Breeding in Mayiladuthurai. Tamil Nadu, South India. Ph.D. Thesis, Bharathidasan University, Thiruchirappali, India.

Asokan, S., A.M.S. Ali and R. Manikannan. 2009. Diet of three insectivorous birds in Nagapattinam District, Tamil Nadu, India - A preliminary study. Journal of Threatened Taxa. 1(6):27-33.

Balasubramanian, P. 1992. New nesting site of the Indian White-throated Kingfisher Halcyon smyrnensis fusca (Boddaert). Journal of Bombay Natural History Society 89:124.

Burton, N.H. 1998. Notes on the diet of nestling White-throated Kingfishers Halcyon smyrnensis in Malaysia. Forktail 14:79-80.

del Hoyo, J., A. Elliot and J. Sargatal. 2001. Handbook of the Birds of the World. Vol 6. Lynx.

Dhindsa, M.S. and H.K. Saini. 1994. Agricultural ornithology: An Indian perspective. Journal of Bioscience 19:391-402.
EcoIndia. 2008. Available at http://www.ecoindia. com/animals/birds/common-kingfisher.html.

Evers, D.C. 1994. Activity budgets of a marked Common Loon (Gavia immer) nesting population. Hydrobiology 279 and 280:415420.

Fry, C.H., K. Fry and A. Harris. 1992. Kingfishers, bee-eaters and rollers. Christopher Helm, London.

Hore, B.B., P.N. Mehrotra and H. Hore. 1991. The rituals of egg laying in Indian White Breasted Kingfisher. Zoo's Print Journal 6(7):9-10.

Husain, K.Z. 1979. Birds of Bangladesh. Eden Press, Dhaka, Bangladesh, 1-84 pp.

Husain, K.Z., S.U. Sarker and M.M. Rahman. 1983. Summer birds of the Sundarbans Nilkamal Sanctuary, Bangladesh. Bangladesh Journal of Zoology 11:48-51.

Islam, M.A., M.M.H. Khan, M.M. Kabir, T. Solhoy, N.B. Jordar and M.M. Feeroz. 1999. Winter birds of the Sundarbans, Bangladesh. Ecoprint 6(1):41-49.

Kelly, J.F. 1998. Behaviour and energy budgets of Belted Kingfishers in winter. Journal of Field Ornithology 69(1):75-84.

Khan, M.A.R. 1982. Wildlife of Bangladesh: A Checklist. University of Dhaka, Dhaka, Bangladesh, $80 \mathrm{pp}$.

Khan, M.A.R. 1986. Wildlife in Bangladesh mangrove ecosystem. Journal of Bombay Natural History Society 83:32-40.

Mukherjee, A.K. 1975. Food-habits of water-birds of the Sundarban, 24 Paraganas District, West Bengal. India-V. Journal of Bombay Natural History Society 72:85-109.

Natarajan, V. 1991. Time budgeting by the Southern Crow-pheasant (Centropus sinensis parroti) at Point Calimere, Tamil Nadu. Journal of Bombay Natural History Society 90:92-95.

Oommen, M. and M.I. Andrews. 1996. Awakening, roosting and vocalization behaviour of the White-throated Kingfisher 
Halcyon smyrnensis fusca (Boddaert). Pavo. 34:43-46.

Oommen, M. and M.I. Andrews. 1998. Food and feeding habits of the White-throated Kingfisher Halcyon smyrnensis. In: Birds in Agriculture Ecosystem. (eds.) Dhindsa, M.S., P. Shyamsunder and B.M. Parasharya. Society for Applied Ornithology (India), pp. 132-136.

Palkar, S.B., R.J. Lovalekar and V.V. Joshi. 2009. Breeding biology of White-throated Kingfisher Halcyon smyrnensis. Indian Birds 4:104-105.

Ramachandran, N.K. 1998. Activity patterns and time budgets of the Pheasant-tailed (Hydrophaslanus chirurgus) and Bronzewinged (Metopidius indicus) Jacanus. Journal of Bombay Natural History Society 95(1):234-245.

Rayner, J., U. Norberg and M. Brooke. 1991. Movement, A survey of modern birds. In: The Cambridge Encyclopedia of Ornithology. $1^{\text {st }}$ edition. (eds.) Brooke, M. and T. Birkhead. The press syndicate of the University of Cambridge, New York, 62 p.

Reza, A.H.M.A., M.M. Ferooz, M.A. Islam and M.M. Kabir. 2003. Status and density of Kingfishers (Family: Alcedinidae, Halcyonidae and Cerylidae) in the Sunderbans mangroves forest, Bangladesh. Bangladesh Journal of Life Science 15(1):55-60.

Roberts, T.J. and C. Priddy. 1965. Food of the White-throated Kingfisher Halcyon smyrnensis (Linnaeus). Journal of Bombay Natural History Society 62(1):152-153.

Rodway, M.S. 1998. Activity patterns, diet and feeding afficiency of Harlequin Ducks breeding in northern Labrador. Canadian Journal of Zoology 76:902-909.

Roza, T. 1995. Crab-eating by White-throated Kingfisher Halcyon smyrnensis (Linn.).
Journal of Bombay Natural History Society 92(1): 121 .

Sarker, S.U. 1985. Density, productivity and biomass of raptorial birds of the Sunderbans, Bangladesh. Proc. SAARC Seminar. Biomass Production, Dhaka, Bangladesh.

Sarker, S.U. 1986. Management of the Wildlife of the Sundarbans. Paper presented at the International Seminar-cum-workshop on wildlife conservation in Bangladesh, Dhaka, Bangladesh.

Sarker, S.U. 1989. Fish eating wildlife and some fishes of the Sundarbans, Bangladesh. Journal of Noami 6(1 and 2): 17-29.

Sen, S.N. 1944. Food of the White-throated Kingfisher (Halcyon smyrnensis fusca). Journal of Bombay Natural History Society 44(3): 475 .

Sirinvasulu, C. 2004. Albinism in White-throated Kingfisher Halcyon smyrnensis (Linn.) from India. Journal of Bombay Natural History Society 101(1): 157.

Sivakumaran, N. and K. Thiyagesan. 2003. Population, diurnal activity patterns and feeding ecology of the Indian Roller (Coracias benghalensis). Zoo's Print Journal 18:10911095.

Soud, R., K. Mazumdar and A. Gupta. 2010. Predation by White-throated Kingfisher Halcyon smyrnensis on Common wolf Snake Lycodon aulicus (Linnaeus). Ne. Biology 1(1):53-54.

Wikipedia. 2010. Available at http://en. wikipedia.org/wiki/Common_Kingfisher.

Yahya, H.S. and S. Yasmin. 1991. Earthworms in the dietary of the White-throated Kingfisher Halcyon smyrnensis (Linn.). Journal of Bombay Natural History Society 88:454.

*Paper was not originally seen. 